ADDENDUM

https://doi.org/10.1038/s41586-019-1586-4

\title{
Editorial Expression of Concern: \\ Global analysis of streamflow response to forest management
}

Jaivime Evaristo \& Jeffrey J. McDonnell

Addendum to: Nature https://doi.org/10.1038/s41586-019-1306-0, published online 17 June 2019.

The editors of Nature have become aware that this Article contains at least two serious technical errors. First, the assembled dataset of paired watershed studies, used to assess the streamflow response to forest removal and planting, contains errors in the percentage change in streamflow associated with land cover modifications. Second, the effects of continent-wide forest removal on streamflow (shown in Table 1) are overestimated, because the authors assumed a starting condition of $100 \%$ forest cover. We are aware that other technical concerns have also been raised; we are investigating these critiques and will provide an update once a resolution has been reached. The authors have been informed of this Editorial Expression of Concern, and are in agreement. 